Article

\title{
Visible Light-Induced Degradation of Methylene Blue in the Presence of Photocatalytic ZnS and CdS Nanoparticles
}

\author{
Nayereh Soltani ${ }^{1{ }^{1} *}$, Elias Saion ${ }^{1}{ }^{1} *$, Mohd Zobir Hussein ${ }^{2}$, Maryam Erfani ${ }^{1}$, Alam Abedini ${ }^{1}$, \\ Ghazaleh Bahmanrokh ${ }^{1}$, Manizheh Navasery ${ }^{1}$ and Parisa Vaziri ${ }^{3}$
}

1 Department of Physics, Faculty of Science, University Putra Malaysia, 43400UPM Serdang, Selangor, Malaysia; E-Mails: maria_395@yahoo.com (M.E.); abedini_alam@yahoo.com (A.A.); ghazalehbahmanrokh@yahoo.com (G.B.); navaseri@gmail.com (M.N.)

2 Department of Chemistry, Faculty of Science, University Putra Malaysia, 43400UPM Serdang, Selangor, Malaysia; E-Mail: mzobir@science.upm.edu.my

3 Department of Medical Physics and Biomedical Engineering, Shahid Beheshti University of Medical Sciences, Iran; E-Mail: parisa_vaziri@ymail.com

* Authors to whom correspondence should be addressed; E-Mails: nayereh.soltani@gmail.com (N.S.); elias@science.upm.edu.my (E.S.); Tel.: +60-1-4736-7961 (N.S.); +60-3-8946-6654 (E.S.).

Received: 4 July 2012; in revised form: 27 August 2012 / Accepted: 4 September 2012 /

Published: 25 September 2012

Abstract: $\mathrm{ZnS}$ and $\mathrm{CdS}$ nanoparticles were prepared by a simple microwave irradiation method under mild conditions. The obtained nanoparticles were characterized by XRD, TEM and EDX. The results indicated that high purity of nanosized $\mathrm{ZnS}$ and CdS was successfully obtained with cubic and hexagonal crystalline structures, respectively. The band gap energies of $\mathrm{ZnS}$ and $\mathrm{CdS}$ nanoparticles were estimated using UV-visible absorption spectra to be about 4.22 and $2.64 \mathrm{eV}$, respectively. Photocatalytic degradation of methylene blue was carried out using physical mixtures of $\mathrm{ZnS}$ and $\mathrm{CdS}$ nanoparticles under a $500-\mathrm{W}$ halogen lamp of visible light irradiation. The residual concentration of methylene blue solution was monitored using UV-visible absorption spectrometry. From the study of the variation in composition of $\mathrm{ZnS}$ : $\mathrm{CdS}$, a composition of 1:4 (by weight) was found to be very efficient for degradation of methylene blue. In this case the degradation efficiency of the photocatalyst nanoparticles after $6 \mathrm{~h}$ irradiation time was about $73 \%$ with a reaction rate of $3.61 \times 10^{-3} \mathrm{~min}^{-1}$. Higher degradation efficiency and reaction rate were achieved by increasing the amount of photocatalyst and initial $\mathrm{pH}$ of the solution. 
Keywords: ZnS; CdS; nanoparticles; photocatalytic; visible light; degradation; methylene blue; $\mathrm{pH}$

\section{Introduction}

Textile, paper and some other industrial processes discharge large amounts of colored dye wastewater which is toxic and non biodegradable in most cases and when it reaches the natural water runoff, the impending photosynthetic activity of aquatic plants seriously threatens the whole ecosystem. Over the past several decades, various physical, chemical, and biological techniques for decoloration of dye effluents have been developed. Conventional treatments such as coagulation, flocculation, absorption, adsorption, ultrafiltration, reverse osmosis, and membrane technologies merely concentrate or transfer organic compounds from one phase to another. Destructive techniques such as chemical oxidation and advanced oxidation processes (AOPs) may overcome these problems, but still suffer from high costs and incomplete degradation. Among AOPs, one of the most efficient and economical methods is probably photocatalysis under visible-light irradiation, which does not require additional chemicals and the main component in the solar spectra and indoor illuminations is visible light [1-6].

Photocatalysis is a process by which a semiconductor material absorbs light of energy greater than or equal to its band gap, causing excitations of valence band electrons in the conduction band. Such charge separation leads to the formation of electron-hole pairs which can further generate free radicals in the system for redox of the substrate. The resulting free-radicals such as hydroxyl $(\bullet \mathrm{OH})$ are very efficient oxidizers of organic materials and can degrade pollutants $[3,7]$.

For efficient degradation of dyes, a photocatalyst that has a suitable band gap, flat band potential/energy levels and good adsorption properties in the visible region is needed. In both respects $\mathrm{CdS}$ with a direct band gap of $\sim 2.4 \mathrm{eV}$ is a promising material whose photocatalytic activity may be improved by activating with $\mathrm{ZnS}$ [8,9]. ZnS is a type of II-VI compound semiconductor material with a wide band gap of $\sim 3.7 \mathrm{eV}$ which can absorb light with wavelengths below $380 \mathrm{~nm}$. ZnS nanocrystals are believed to be an effective photocatalyst, resulting from rapid generation of electron-hole pairs and highly negative redox potentials of excited electrons [10-13].

To fully achieve the photocatalysis properties of $\mathrm{ZnS}$ and CdS, a well-defined structure is desirable. Generally, the photocatalytic activity of semiconductor materials can be strongly influenced by their structure and particle size, in which particle size is the most important factor [14]. The reactivity of nanosized semiconductors is often altered or enhanced with respect to their bulk counterparts due to size-dependent changes in their redox potentials and high density of the active surface states associated with large surface-to-volume ratio. Moreover, recombination of electron-hole pairs within the semiconductor particle is drastically reduced as particle size decreases [7,15].

The size and structure of nanoparticles depend upon the synthesis methods and conditions (e.g., temperature, pressure, and composition). Amorphous particles can be crystallized if proper treatment is used to meet the energy requirements. In recent years, several synthesis methods have been successfully developed to prepare semiconductor nanostructures including a hydrothermal 
method [16,17], a solvothermal method [18], a sonochemical method [19,20], gamma-irradiation [21,22], microwave irradiation [23,24] and a micro-emulsion method [25,26]. Among these methods, the microwave assisted route is becoming an increasingly popular method for chemical synthesis. It offers a clean, cheap and convenient method of heating, which often results in higher yields and shorter reaction times and is capable of producing smaller particles with a narrow particle size distribution and high purity $[27,28]$.

Based on previous knowledge of researches, we developed a simple microwave irradiation method for the synthesis of highly crystalline $\mathrm{ZnS}$ and $\mathrm{CdS}$ nanoparticle semiconductor quantum dots to evaluate their photocatalytic activity. The obtained nanoparticles were characterized by XRD, TEM, EDX, and UV-Vis absorption spectroscopy. The photocatalytic activity of the obtained nanostructures was examined using the degradation of methylene blue (MB) under visible light in air at room temperature by considering the influence of experimental parameters such as the $\mathrm{ZnS}$ :CdS weight ratio, the amount of catalyst used and the initial $\mathrm{pH}$ of the solution.

\section{Results and Discussion}

\subsection{Material Characterization}

The formation of $\mathrm{ZnS}$ and $\mathrm{CdS}$ nanoparticles can be observed by the change in color of the solution from colorless to white and yellow respectively and confirmed by powder X-ray diffraction studies.

Figure 1. X-ray diffraction (XRD) pattern of the $\mathrm{ZnS}$ and $\mathrm{CdS}$ nanoparticles.

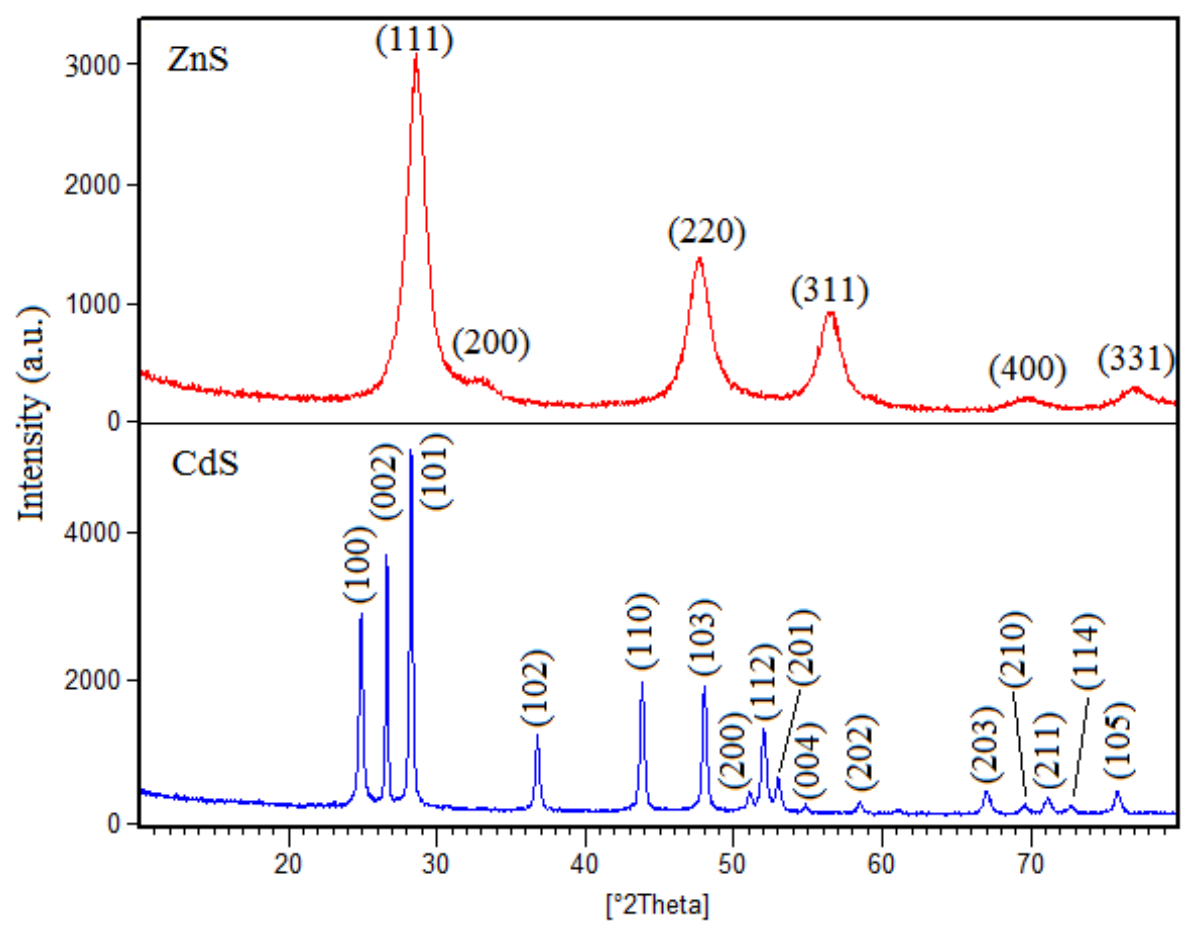

Figure 1 shows the XRD patterns of $\mathrm{ZnS}$ and CdS nanocrystals. In this figure the peaks observed in the XRD patterns of $\mathrm{ZnS}$ nanoparticles at $2 \theta$ values of $28.5^{\circ}, 33.1^{\circ}, 47.4^{\circ}, 56.3^{\circ}, 69.4^{\circ}$ and $76.7^{\circ}$, match perfectly with the (111), (200), (220), (311), (400) and (331) crystalline planes of the face centered cubic structure of $\mathrm{ZnS}$ reported in ICDD PDF 65-1691 with lattice parameter of $5.41 \mathrm{~A}^{\circ}$ and 
cell volume of $158.4 \mathrm{~A}^{03}$. For $\mathrm{CdS}$ nanoparticles, the peaks observed in the XRD patterns at $2 \theta$ values of $24.9^{\circ}, 26.6^{\circ}, 28.3^{\circ}, 36.8^{\circ}, 43.9^{\circ}, 48.1^{\circ}, 51.1^{\circ}, 52.1^{\circ}, 53.1^{\circ}, 54.9^{\circ}, 58.6^{\circ}, 67.1^{\circ}, 69.6^{\circ}, 71.2^{\circ}, 72.8^{\circ}$ and $75.9^{\circ}$ closely match with the (100), (002), (101), (102), (110), (103), (200), (112), (201), (004), (202), (203), (210), (211), (114) and (105) crystalline planes of the hexagonal structure of CdS in the reference pattern of ICDD PDF 80-0006 with the crystal lattice parameters of 4.12, 4.12 and $6.68 \mathrm{~A}^{\circ}$ and cell volume of $98.27 \mathrm{~A}^{03}$. In both patterns no peaks corresponding to impurities were detected, indicating high purity of the products.

To confirm purity of the products the chemical compositions of $\mathrm{ZnS}$ and $\mathrm{CdS}$ nanoparticles were analyzed using Energy-dispersive X-ray spectroscopy (EDX). The EDX patterns of nanoparticles are shown in Figure 2 and the related data are listed in Table 1. The results verify the high purity of the nanoparticles.

Figure 2. EDX pattern of (a) $\mathrm{ZnS}$ and (b) $\mathrm{CdS}$ nanoparticles.

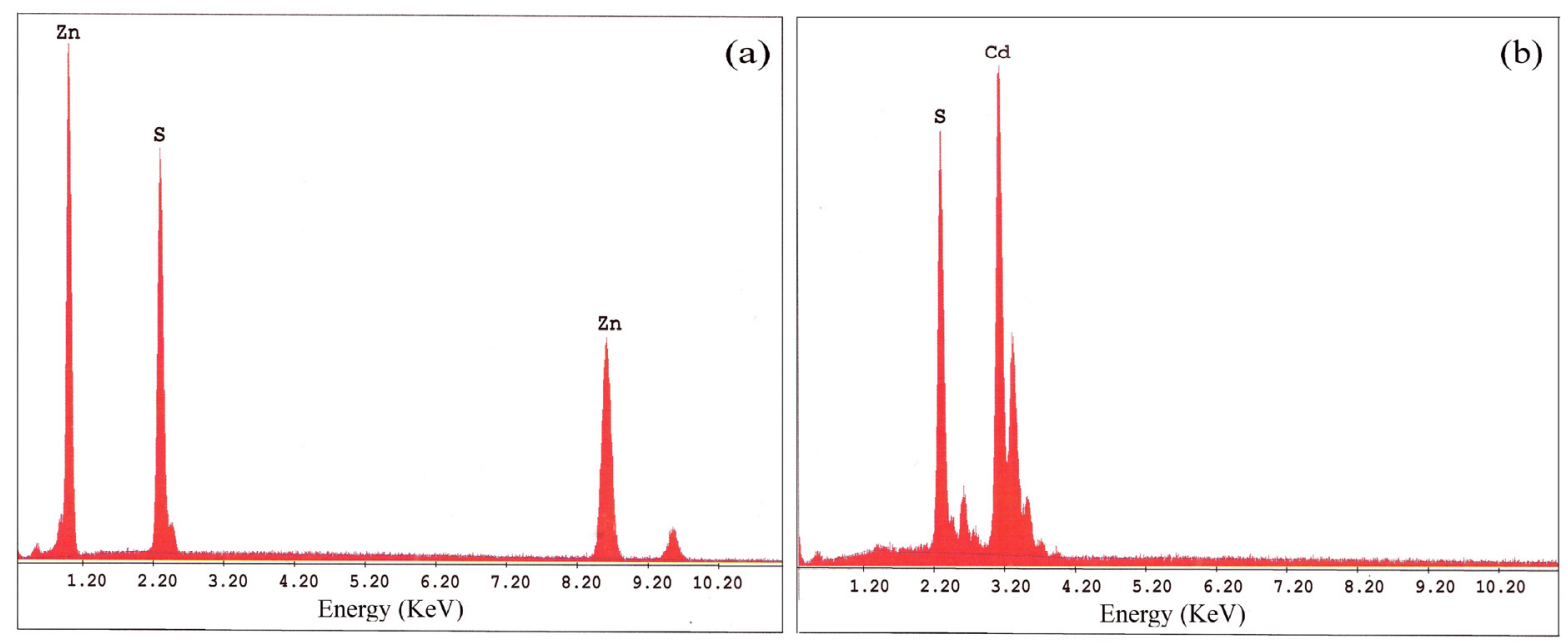

Table 1. Energy-dispersive X-ray spectroscopy (EDX) data of ZnS and CdS nanoparticles.

\begin{tabular}{cccc}
\hline Sample & Element & wt\% & At\% \\
\hline \multirow{3}{*}{$\mathrm{ZnS}$} & $\mathrm{S}$ & 30.63 & 47.37 \\
& $\mathrm{Zn}$ & 69.37 & 52.63 \\
& total & 100.00 & 100.00 \\
\hline \multirow{2}{*}{$\mathrm{CdS}$} & $\mathrm{S}$ & 21.13 & 48.44 \\
& $\mathrm{Cd}$ & 78.87 & 51.56 \\
& total & 100.00 & 100.00 \\
\hline
\end{tabular}

Figure 3 shows the TEM images and corresponding size distribution histogram of $\mathrm{ZnS}$ nanoparticles. The figure indicates that $\mathrm{ZnS}$ nanoparticles are small spherical particles with a size of less than $7 \mathrm{~nm}$ having a relatively narrow homogeneous distribution which appears aggregated. The estimated average particle size is about $4.3 \mathrm{~nm}$.

The TEM images and corresponding size distribution histogram of CdS nanoparticles are shown in Figure 4. The figure shows that CdS nanoparticles are approximately monodispersed particles of larger sizes, estimated to be between 6 and16 nm with an average particle size of $10.1 \mathrm{~nm}$. 
Figure 3. TEM image and particle size distribution histogram of $\mathrm{ZnS}$ nanoparticles.
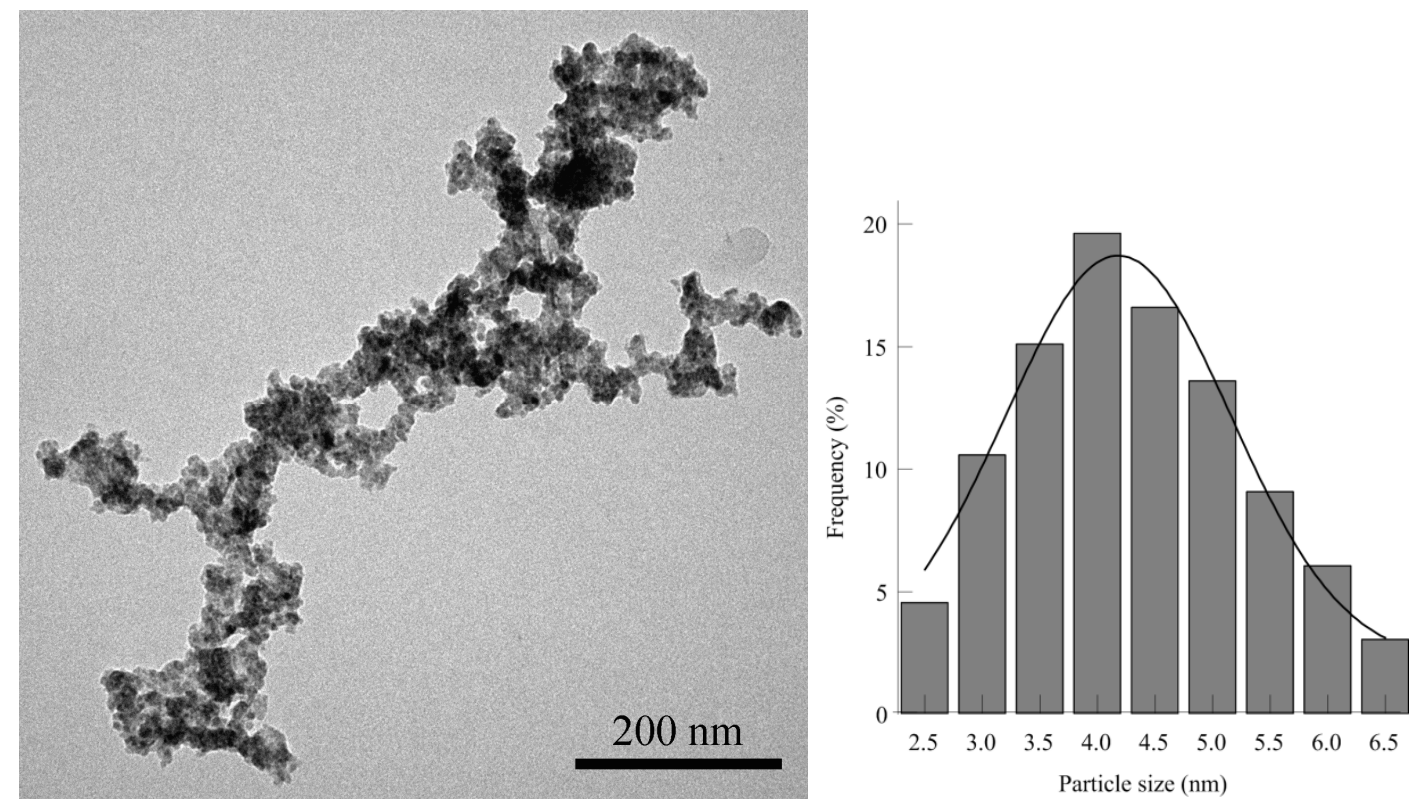

Figure 4. TEM image and particle size distribution histogram of CdS nanoparticles.
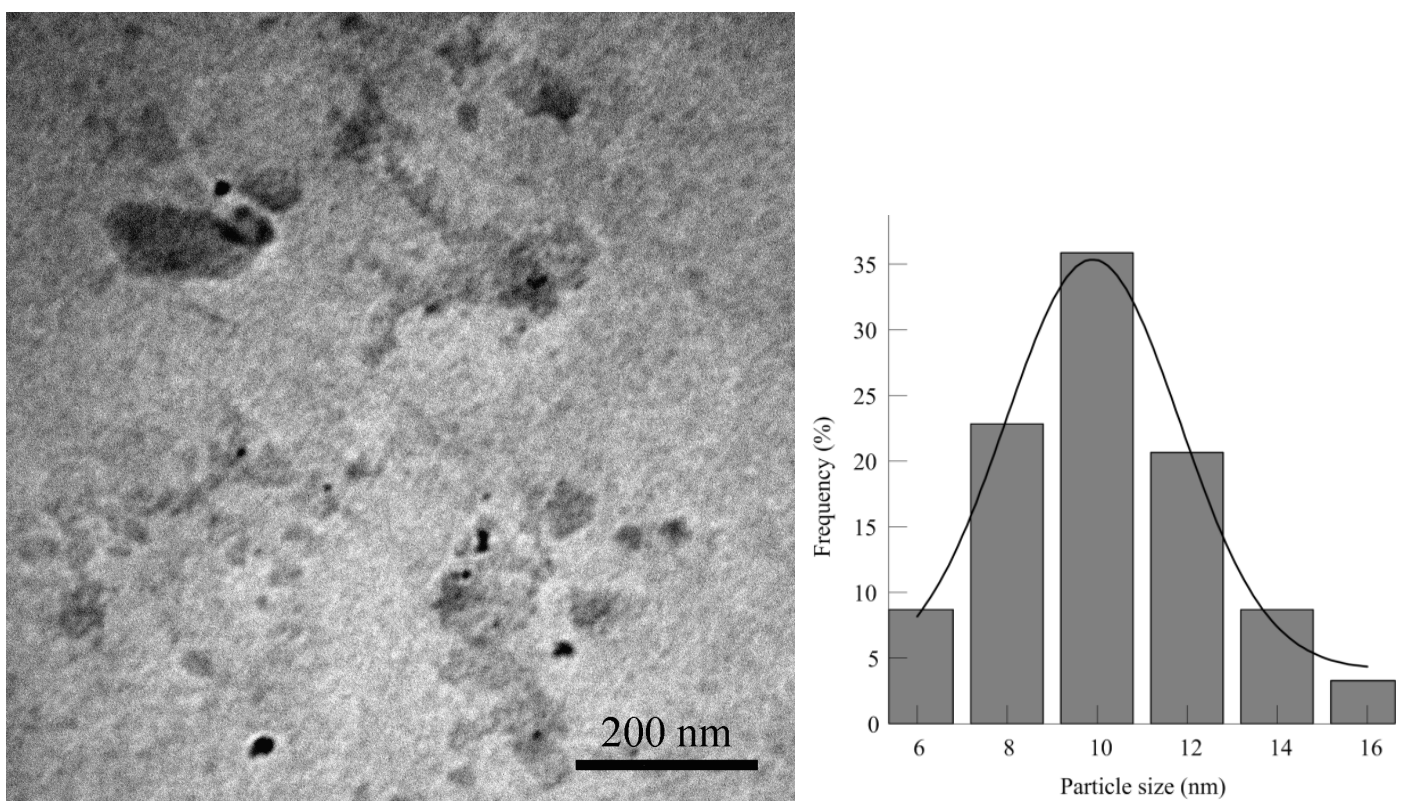

The band gap energy $(E \mathrm{~g})$ of $\mathrm{ZnS}$ and CdS nanoparticles can be evaluated from the UV-Vis spectra by Tauc plot of $(h v \alpha)^{2}$ versus $(h v)$ and extrapolation of the linear portions of the curves to the energy axis according to [29]:

$$
\alpha h v=B\left(h v-E_{g}\right)^{1 / 2}
$$

where $\alpha$ is the absorption coefficient, $h v$ is the photon energy, $E_{g}$ is the direct band gap energy, and $B$ is a constant. The absorption coefficient $(\alpha)$ was determined from the relation $A=I / I_{0}=e^{(-\alpha d)}$, or it can be calculated using the well-known relation deduced from Beer-Lambert's relation, $\alpha=2.303 \mathrm{~A} / \mathrm{d}$, where $d$ is the path length of the quartz cuvette and $A$ is the absorbance determined from the UV-visible spectrum [30]. UV-Vis absorption spectra and the Tauc plot of $\mathrm{ZnS}$ and CdS nanoparticles are shown 
in Figures 5 and 6. The blue shift of absorption edge compared to their bulk counterparts clearly explains the quantum confinement effect of the nanoparticles. The estimated optical band gaps of $\mathrm{ZnS}$ and CdS nanoparticles are about $4.22 \mathrm{eV}$ and $2.64 \mathrm{eV}$, respectively.

Figure 5. UV-Vis absorption spectra and Tauc plot of the $\mathrm{ZnS}$ nanoparticles.

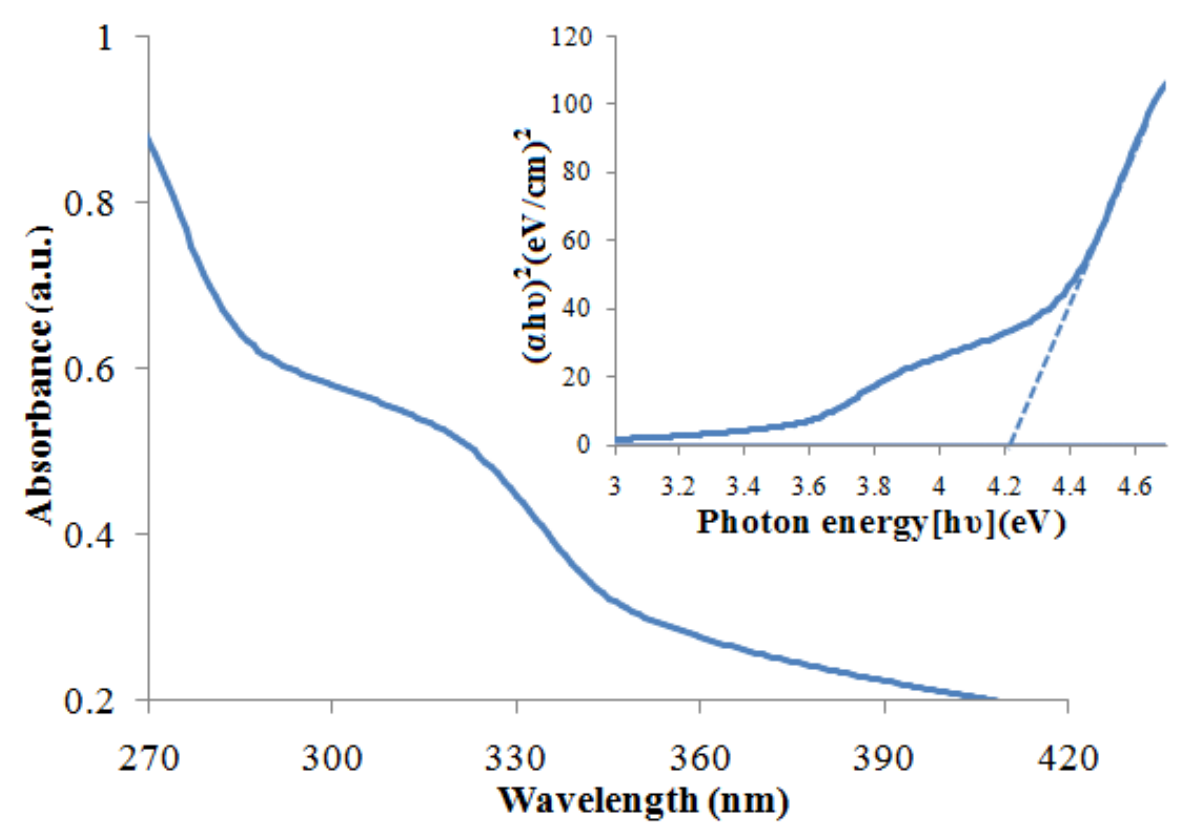

Figure 6. UV-Vis spectra and Tauc plot of the CdS nanoparticles.

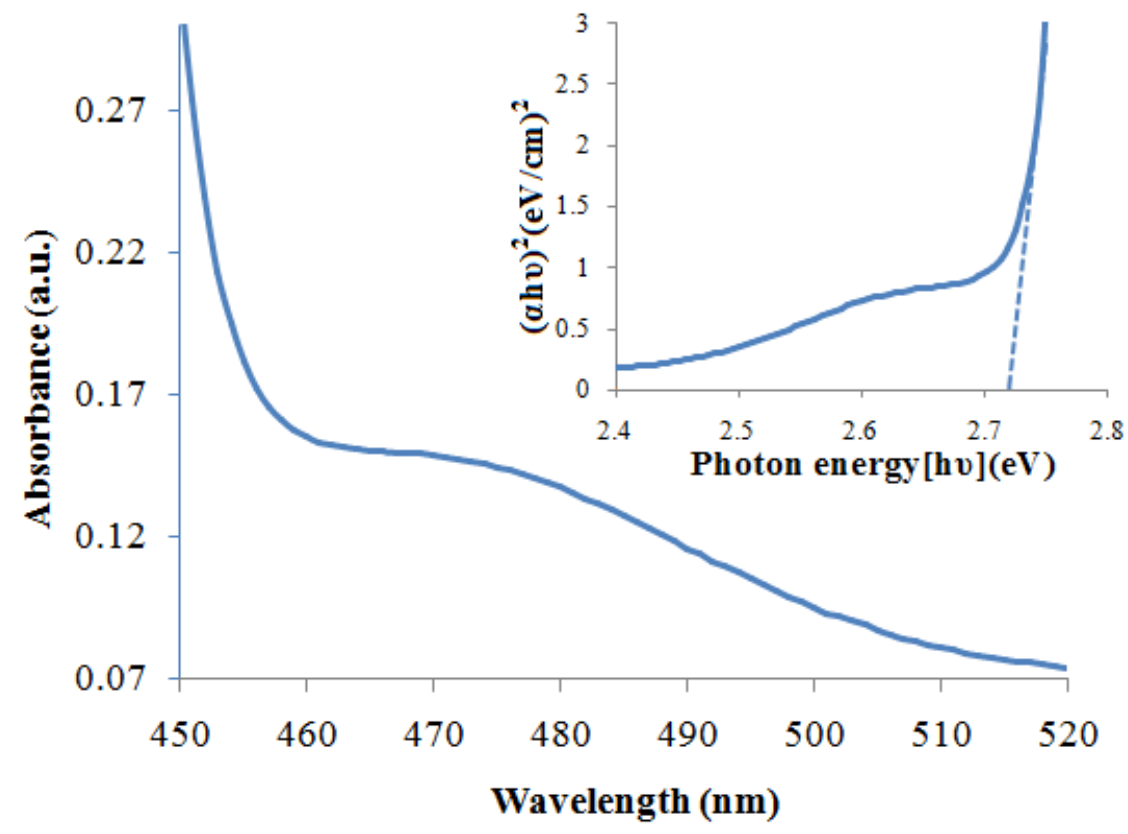

\subsection{Photodegradation Process}

In the presence of air or oxygen, the irradiated semiconductor nanoparticles are capable of destroying many organic contaminants. The activation of $\mathrm{ZnS}$ and $\mathrm{CdS}$ by light (hv) produces electron-hole pairs which are powerful oxidizing and reducing agents, respectively: 


$$
\mathrm{ZnS}+h v \rightarrow \mathrm{h}^{+}+\mathrm{e}^{-} \quad \text { and } \quad \mathrm{CdS}+h v \rightarrow \mathrm{h}^{+}+\mathrm{e}^{-}
$$

The oxidative and reductive reactions are expressed as:

$$
\mathrm{OH}^{-}+\mathrm{h}^{+} \rightarrow \cdot \mathrm{OH} \quad \text { and } \quad \mathrm{O}_{2}+\mathrm{e}^{-} \rightarrow \mathrm{O}_{2}^{-}
$$

In the degradation of organic compounds (MB), the hydroxyl radical which comes from the oxidation of adsorbed water or adsorbed $\mathrm{OH}^{-}$, is the primary oxidant; and the presence of oxygen can prevent the re-combination of hole-electron pairs. For a complete reaction, the final products of the reaction among others are $\mathrm{CO}_{2}$ and $\mathrm{H}_{2} \mathrm{O}[31,32]$ :

$$
\mathrm{MB}+\cdot \mathrm{OH} \rightarrow \text { products }\left(\mathrm{CO}_{2}+\mathrm{H}_{2} \mathrm{O}+\mathrm{NH}_{4}{ }^{+}+\mathrm{NO}_{3}{ }^{-}+\mathrm{SO}_{4}{ }^{2-}+\mathrm{Cl}^{-}\right)
$$

\subsubsection{Influence of Catalyst Composition}

Figures 7 and 8 show the photodegradation of MB in terms of absorption spectra and as a function of irradiation time in the presence of $\mathrm{ZnS}$ and $\mathrm{CdS}$ nanoparticles under visible light, respectively. The photodegradation of $\mathrm{MB}$ was monitored as the normalized change in its concentration also using degradation efficiency. The intersection of these two curves $\left(C / C_{0}\right.$ and $\left.1-C / C_{0}\right)$ shows the half-life of $\mathrm{MB}$, which is the time taken for the concentration of $\mathrm{MB}$ to decrease by half. From these figures, it could be seen that the intensity of the adsorption peaks diminished gradually as the exposure time increased, which is more pronounced in the case of using $\mathrm{CdS}$ as a photocatalyst. Thereby the normalized concentration change of $\mathrm{MB}$ in the presence of $\mathrm{CdS}$ nanoparticles is greater than in the presence of $\mathrm{ZnS}$ so that for $\mathrm{CdS}$ photocatalyst, the concentration of MB has decreased by half after $210 \mathrm{~min}$ and the degradation efficiency has reached $63 \%$ after $360 \mathrm{~min}$ while for $\mathrm{ZnS}$, the efficiency was only nearly $30 \%$ after $360 \mathrm{~min}$.

Figure 7. Absorption spectral changes and photodegradation of methylene blue (MB) aqueous solution degraded by $\mathrm{ZnS}$ nanoparticles under visible light.
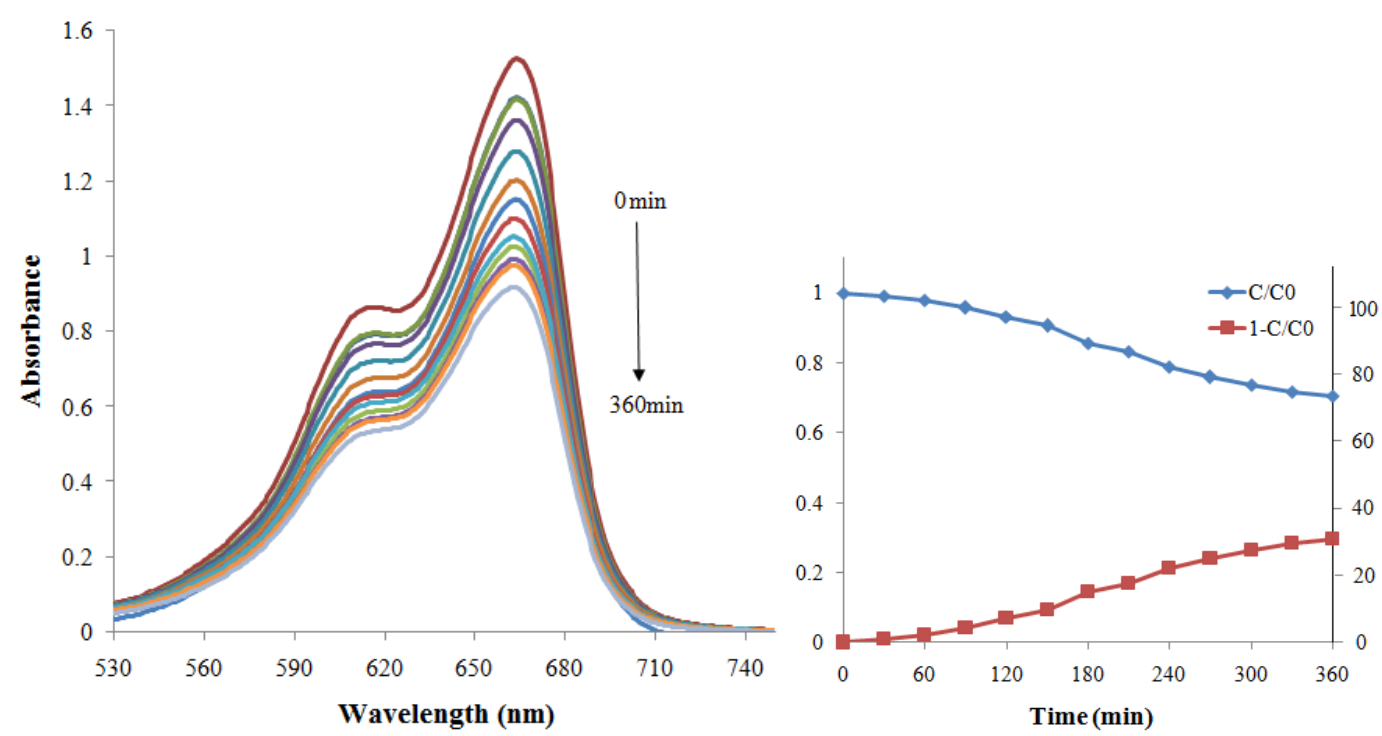
Figure 8. Absorption spectral changes and photodegradation of $\mathrm{MB}$ aqueous solution degraded by CdS nanoparticles under visible light.
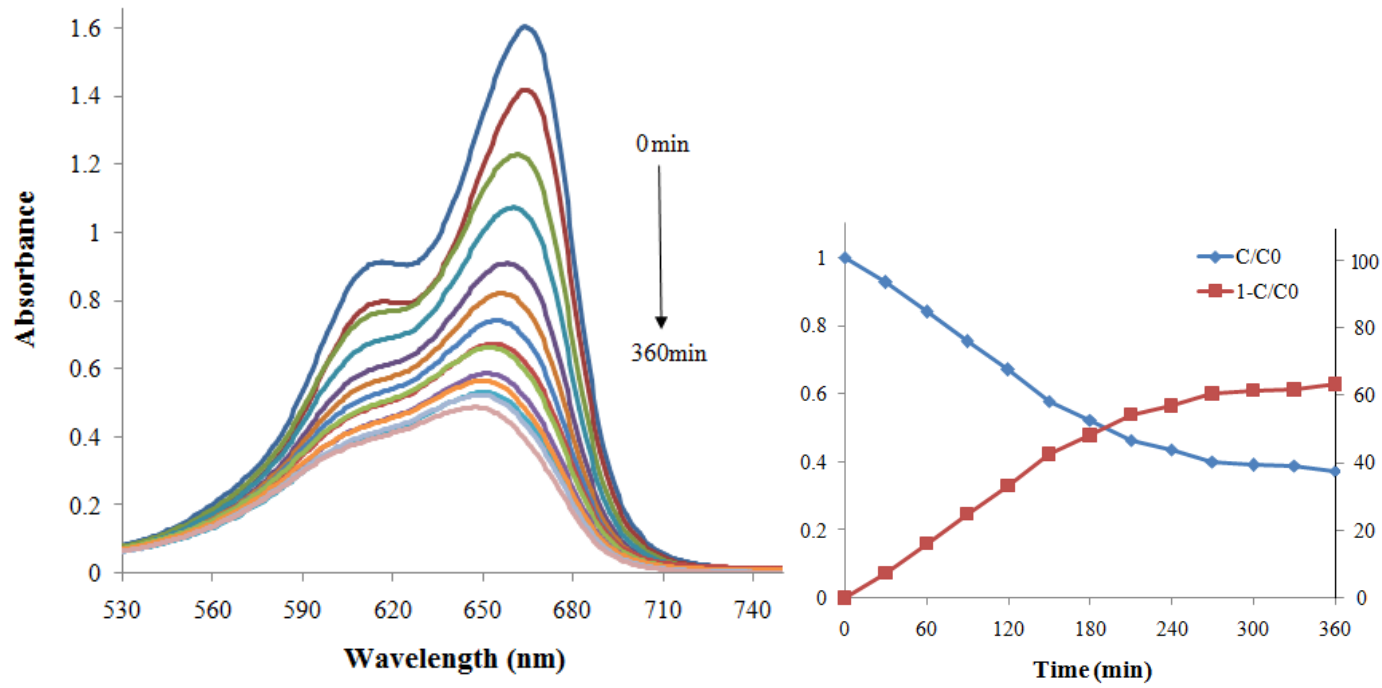

For a photocatalyst to show visible-light activity, a small band gap is also important. Another major criterion for the degradation of organic compound is that the redox potential of the $\mathrm{H}_{2} \mathrm{O} / \cdot \mathrm{OH}$ $\left(\mathrm{OH}^{-}=\cdot \mathrm{OH}+\mathrm{e}^{-} ; E^{\mathrm{o}}=-2.8 \mathrm{~V}\right)$ couple lies within the band gap of the semiconductor [33].

The difference in photocatalytic activities of $\mathrm{ZnS}$ and $\mathrm{CdS}$ nanoparticles is strongly related to their band gap. As a result of its large band gap, $\mathrm{ZnS}$ gives a poor response to visible light, although its conduction band (CB) bottom potential is sufficiently negative $(-1.0 \mathrm{eV}$ vs. the standard hydrogen electrode (SHE) as shown in Figure 9). In contrast, the small band gap of CdS makes it a good absorber of visible light but the $\mathrm{CB}$ bottom potential of $\mathrm{CdS}$ is close to that of $\mathrm{O}_{2} / \mathrm{O}_{2}{ }^{-}(-0.046 \mathrm{eV} v \mathrm{~s}$. SHE), indicating that it readily undergoes photocorrosion in aqueous media containing oxygen and the over potential is too small to reduce $\mathrm{O}_{2}$ with the photoexcited electrons [34], therefore CdS also shows relatively low degradation efficiency ( $\sim 63 \%$ after $6 \mathrm{~h})$. In addition to band gap, the particle size, surface area, crystal structure and degree of crystallinity of $\mathrm{ZnS}$ and $\mathrm{CdS}$ nanoparticles also have influence on the transportation of photogenerated electrons and holes and subsequently their photocatalyst performance.

Figure 9. Schematic band structure of $\mathrm{ZnS}$ and $\mathrm{CdS}$ nanoparticles.

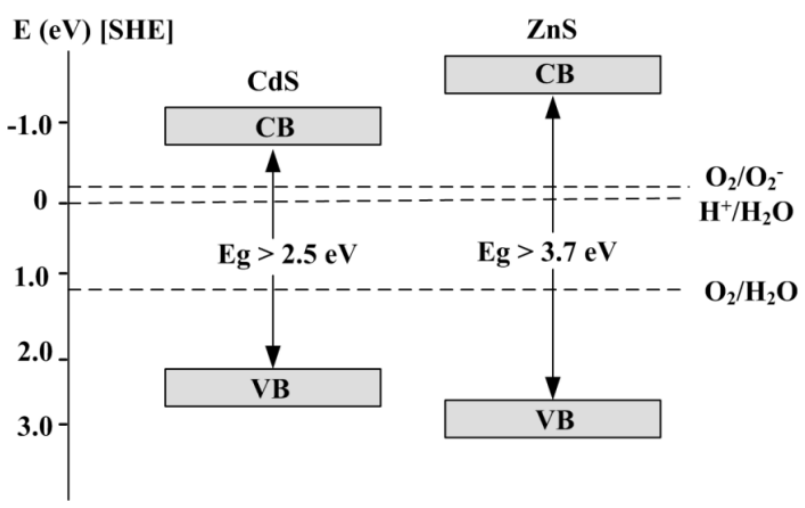


To increase overall photocatalyst activity of bare $\mathrm{ZnS}$ and $\mathrm{CdS}$ nanoparticles, a series of experiments was carried out on physical mixtures of them with different weight percentages. For comparison the normalized concentration changes of $\mathrm{MB}$ in the absence of photocatalyst but under similar exposure to visible light were measured and compared with those determined in the presence of $\mathrm{ZnS}$ and $\mathrm{CdS}$ photocatalyst mixture as shown in Figure 10. The related photodegradation data are reported in Table 2.

Figure 10. Photodegradation of $\mathrm{MB}$ in the presence of $\mathrm{ZnS}$ and $\mathrm{CdS}$ nanoparticle mixtures with different $\mathrm{ZnS}$ weight percentages under visible light.

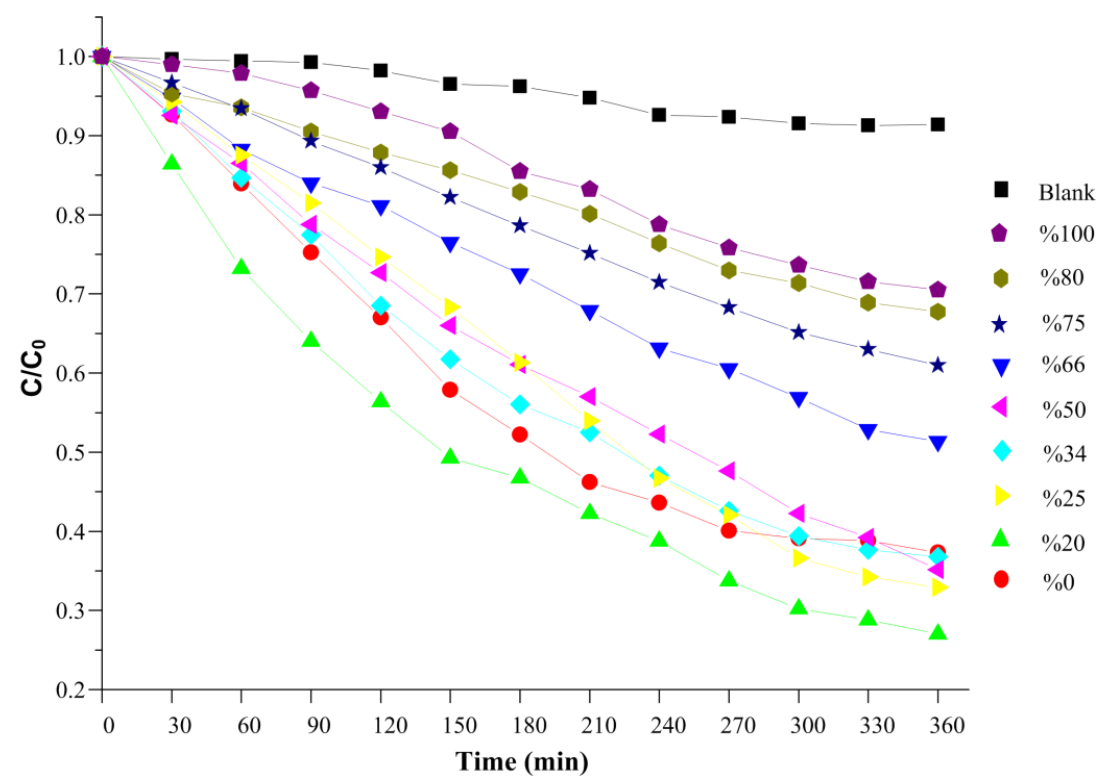

Table 2. Photodegradation data of $\mathrm{MB}$ in the presence of $\mathrm{ZnS}$ and $\mathrm{CdS}$ mixtures.

\begin{tabular}{ccccccc}
\hline Sample & ZnS:CdS & $\begin{array}{c}\text { wt\% ZnS } \\
(\mathbf{m g})\end{array}$ & $\begin{array}{c}\text { wt\% CdS } \\
(\mathbf{m g})\end{array}$ & $\begin{array}{c}\text { Half-life } \\
(\mathbf{m i n})\end{array}$ & $\begin{array}{c}\text { Degradation } \\
\text { efficiency\% }\end{array}$ & $\begin{array}{c}\text { Rate const. after 360 } \mathbf{m i n} \\
\left(\times \mathbf{1 0}^{-\mathbf{3}}\left(\mathbf{m i n}^{\mathbf{- 1}}\right) \mathbf{)}\right.\end{array}$ \\
\hline 1 & $(1: 0)$ & 100 & 0 & - & 30 & 1.09 \\
2 & $(4: 1)$ & 80 & 20 & - & 32 & 1.11 \\
3 & $(3: 1)$ & 75 & 25 & - & 39 & 1.43 \\
4 & $(2: 1)$ & 66 & 34 & 360 & 49 & 1.88 \\
5 & $(1: 1)$ & 50 & 50 & 270 & 65 & 2.89 \\
6 & $(1: 2)$ & 34 & 66 & 240 & 63 & 2.99 \\
7 & $(1: 3)$ & 25 & 75 & 240 & 67 & 3.37 \\
8 & $(1: 4)$ & 20 & 80 & 150 & 73 & 3.61 \\
9 & $(0: 1)$ & 0 & 100 & 210 & 63 & 2.98 \\
\hline
\end{tabular}

It is apparent from Table 2 that the degradation efficiency of physical mixtures in the degradation of MB has two maxima (Figure 11). It is worth noting that similar results have been reported by other authors for composite CdS-ZnS photocatalysts in hydrogen production [35,36]. The photocatalytic activity increases with decreasing $\mathrm{ZnS}$ weight percentage to $50 \%$, then decreases and again increases and reaches its highest amount of $73 \%$ for a $\mathrm{ZnS}$ percentage of $20 \%$ which corresponds to the minimum half-life of $150 \mathrm{~min}$. Accordingly, for the physical mixtures, the photodegradation efficiency 
should be related to the interaction between the two components and cannot simply be determined by the $\mathrm{ZnS}$ weight fraction.

Figure 11. Degradation efficiency of $\mathrm{MB}$ in the presence of physical mixtures of $\mathrm{ZnS}$ and CdS.

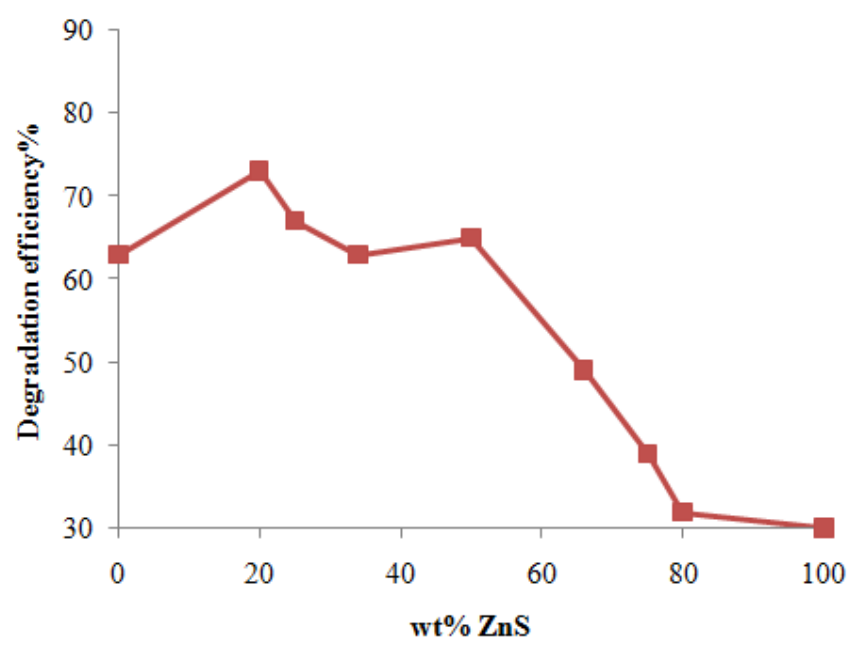

Figure 12 shows the linear plots of $\operatorname{Ln}\left(C / C_{0}\right)$ for the photodegradation of MB with physical mixtures of $\mathrm{ZnS}$ and $\mathrm{CdS}$ under visible light after $360 \mathrm{~min}$ illumination. The slopes of the plots which represent the photocatalyst reaction rate constants were calculated and listed in Table 2. It can be seen from this table that the reaction rate of physical mixtures in the degradation of MB increases with increasing $\mathrm{ZnS}$ weight percentage and reaches its maximum at a $\mathrm{ZnS}$ percentage of $20 \%$. The maximum reaction rate is $3.61 \times 10^{-3} \mathrm{~min}^{-1}$.

Figure 12. Linear plots of $\operatorname{Ln}\left(C / C_{0}\right)$ for the photodegradation of $\mathrm{MB}$ in the presence of physical mixtures of $\mathrm{ZnS}$ and $\mathrm{CdS}$ with different $\mathrm{ZnS}$ weight percentages under visible light.

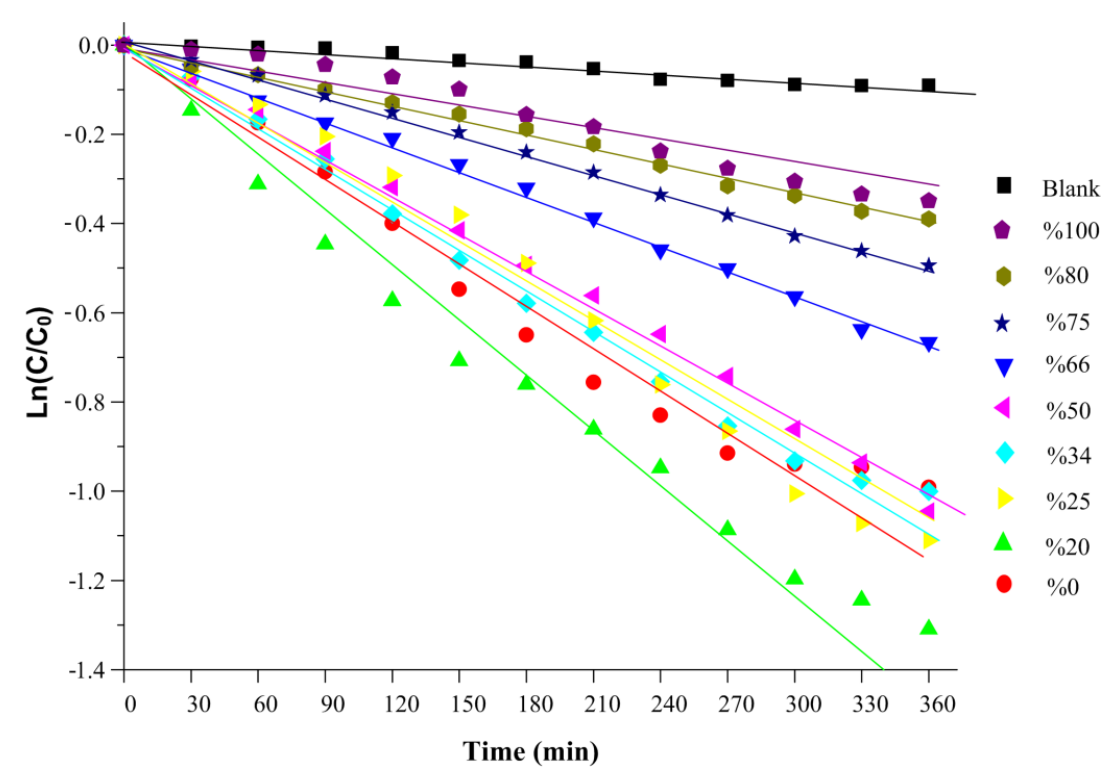




\subsubsection{Influence of Catalyst Amount}

The effect of the catalyst amount on the MB photodegradation (Figure 13) was investigated for $\mathrm{ZnS}: \mathrm{CdS} 20 \%$, since this was the material with the best photocatalytic activity. The rate of MB degradation is dependent on the photocatalyst concentration. With increasing catalyst concentration both the number of dye molecules adsorbed and the number of photons absorbed were increased which promotes the degradation rate. However for very high concentrations of catalyst the suspension's turbidity increases which decreases the light penetration and consequently the photodegradation is less effective [37].

Figure 13. Effect of catalyst amount on the MB decolorization process ( $\mathrm{ZnS}$ :CdS 20\%).

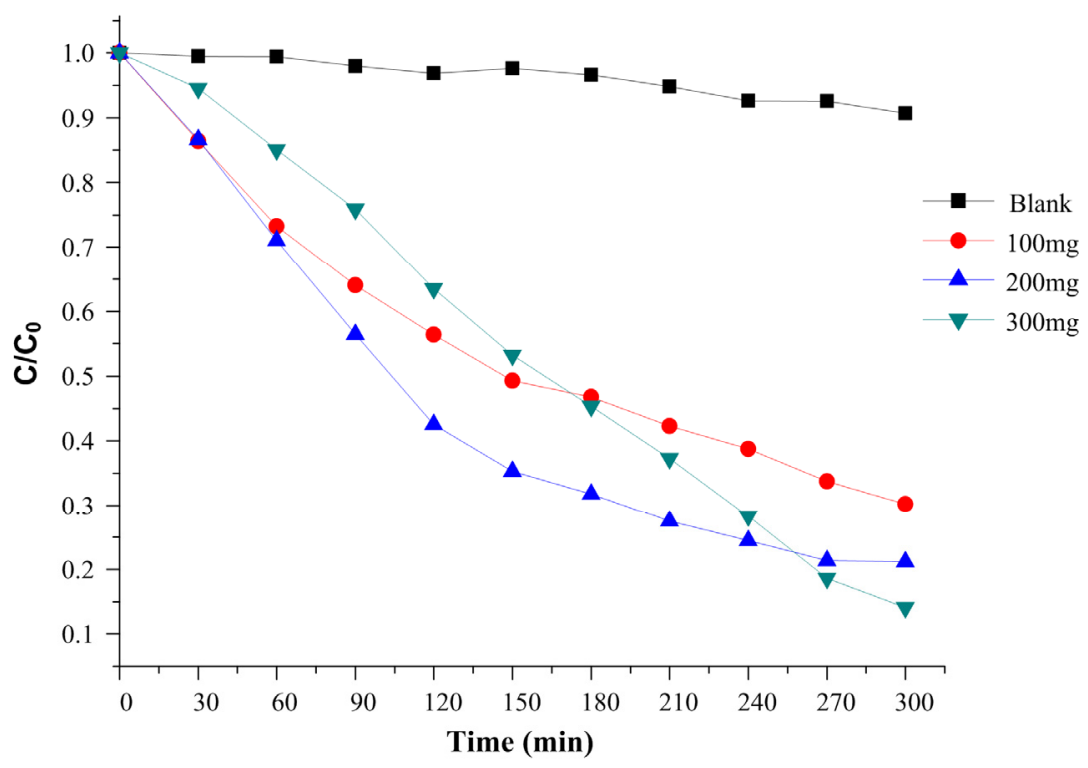

\subsubsection{Influence of the $\mathrm{pH}$}

Usually for industrial waste water characteristics, the $\mathrm{pH}$ is one of the most important parameters that influences the photo-oxidation process. The effect of the $\mathrm{pH}$ on the degradation rate, is due to the modification of the electrical double layer of the solid electrolyte interface, which affects the adsorption-desorption processes and the separation of the photogenerated electron-hole pairs in the surface of the catalyst particles [37].

The surfaces of photocatalysts are positively charged in acidic solutions and negatively charged in alkaline solutions [38]. As a result, the efficiency of the MB photodegradation is expected to increase with $\mathrm{pH}$ owing to the electrostatic interactions between the negative photocatalyst's surface and the $\mathrm{MB}$ cations. Moreover, at high $\mathrm{pH}$, the most favorable for sulfur-containing organic oxidation, the photocatalyst corrosion is minimal [39].

It is a well known process in an acidic or alkaline solution that MB degradation is due to the change in hydrogen concentration of the solution towards higher $\mathrm{pH}$. However, in a solution containing MB and quantum dots such as $\mathrm{ZnS}: \mathrm{CdS}$ used as catalysts, the effect of MB photodegradation does not change with the $\mathrm{pH}$ of the solution. To show this we did $\mathrm{MB}$ photodegradation experiments in solutions at three different $\mathrm{pHs}$ to evaluate the effect of $\mathrm{ZnS}: \mathrm{CdS}$ catalysts in acidic and alkaline 
solutions. The ability of the MB to be adsorbed on the photocatalyst's surface was tested using suspensions of $\mathrm{MB}$ and $\mathrm{ZnS}: \mathrm{CdS}(20 \%)$ under dark conditions (Figure 14). For pH 5 a slight adsorption onto the photocatalysts surface was observed during light-off (first $30 \mathrm{~min}$ ) which is due to the cationic behavior of both, $\mathrm{ZnS}$ :CdS and MB. Conversely, for $\mathrm{pH} 10$ a very high amount of the dye was adsorbed. For neutral $\mathrm{pH}$ an intermediate adsorption situation was observed.

Figure 14. Photocatalytic decolorization of $\mathrm{MB}$ solution using different initial $\mathrm{pH}$ values (100 mg ZnS:CdS 20\%).

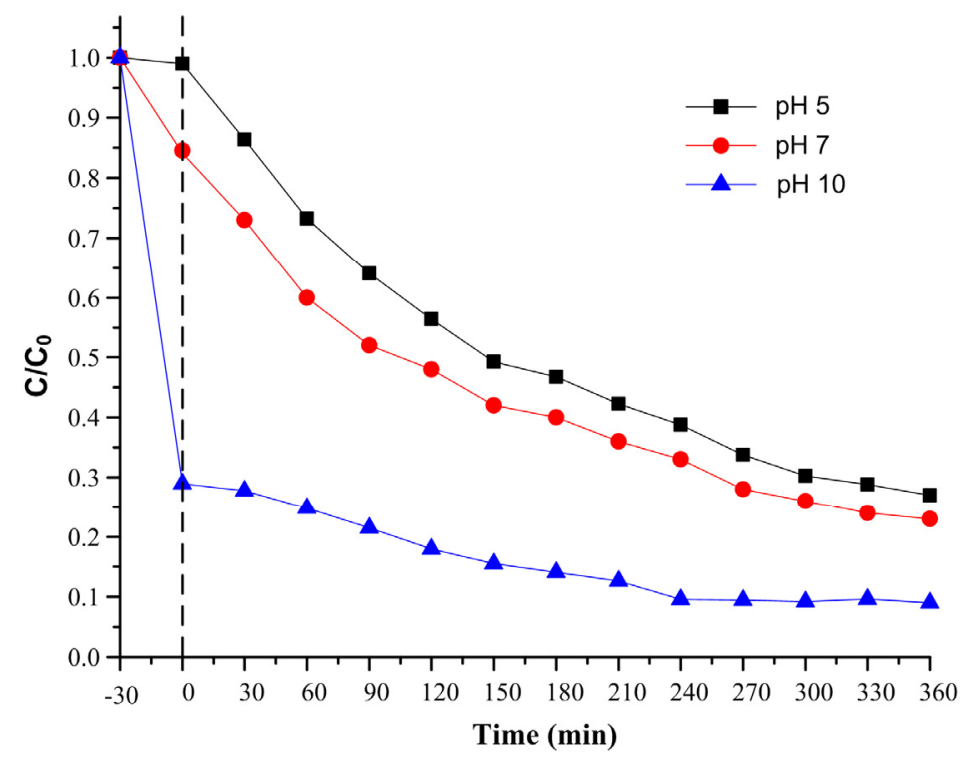

\section{Experimental Section}

\subsection{Preparation of $Z n S$ and $C d S$ Nanoparticles}

The starting materials for the synthesis of $\mathrm{ZnS}$ and $\mathrm{CdS}$ nanoparticles were zinc acetate ( $\mathrm{R} \& \mathrm{M}$ Chemical) and cadmium chloride (Acros Organics) as zinc and cadmium sources respectively, thioacetamide as a sulfur source and ethylene glycol as a solvent. All chemicals were analytical grade products and used without further purification.

In a typical synthesis, $0.005 \mathrm{M}$ of zinc or cadmium source and $0.006 \mathrm{M}$ of sulfur source were added in a glass beaker of $100 \mathrm{~mL}$ containing $20 \mathrm{~mL}$ of solvent. The solution was stirred at $500 \mathrm{rpm}$ for $30 \mathrm{~min}$. The beaker was placed in a high power microwave oven $(1100 \mathrm{~W})$ operated using a pulse regime with $20 \%$ power for 25 min irradiation time. The formed precipitates were centrifuged (3500 rpm, $10 \mathrm{~min}$ ) and the residue was washed several times with distilled water and absolute ethanol. The products were dried in air at $60{ }^{\circ} \mathrm{C}$ for $24 \mathrm{~h}$ under control environment. The products were characterized by X-ray diffraction (XRD) at a scanning rate of $5^{\circ} / \mathrm{min}$ in the $2 \theta$ range $20^{\circ}-70^{\circ}$ using a Philips X-ray diffractometer (7602 EA Almelo, the Netherlands) with $\mathrm{Cu} K \alpha$ radiation $(\lambda=0.1542 \mathrm{~nm})$. The particle size and size distribution were determined from transmission electron microscopy (TEM) micrographs (HTACHI H-7100 TEM, Chula Vista, CA, USA) operating at $100 \mathrm{keV}$. The optical properties of $\mathrm{ZnS}$ and $\mathrm{CdS}$ nanoparticles were characterized using UV-visible absorption spectroscopy (UV-1650PC SHIMADZU, Columbia, MD, USA). 


\subsection{Photocatalytic Reaction}

The photocatalytic reactor (Figure 15) is a cylindrical Pyrex-glass cell with $1.0 \mathrm{~L}$ capacity. A 500-W halogen lamp as the visible light source (emission range of 400-800 nm) was placed in a quartz lamp holder which was immersed in the photoreactor cell. The cell was filled with $0.6 \mathrm{~L}$ of $10 \mathrm{mg} / \mathrm{L}$ of MB solution and $100 \mathrm{mg} / \mathrm{L}$ of nanoparticles as photocatalyst. The whole reactor was cooled with an electric fan from outside the cell and the temperature was kept at $25^{\circ} \mathrm{C}$. All reactants in the reaction cell were stirred using a magnetic stirrer while fresh air bubbles were introduced into the suspension using a pump. Analogous control experiments were performed without the photocatalyst nanoparticles (blank). The degradation of MB was monitored by taking $4 \mathrm{~mL}$ of the suspension at the irradiation time intervals $(30 \mathrm{~min})$. Each time the suspension was centrifuged to separate the photocatalyst particles from the MB solution. Subsequently, the degradation rate was calculated according to the change in absorbance of the dye solution.

Figure 15. Schematic diagram of the photocatalytic reactor system.

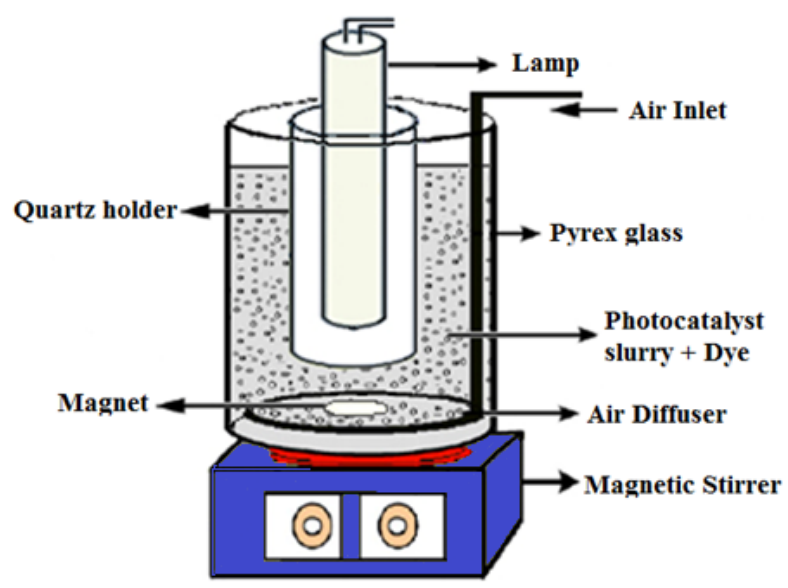

The absorption spectra of the samples were recorded by measuring the absorbance at $664 \mathrm{~nm}$ corresponding to the maximum absorption wavelength of $\mathrm{MB}$ with UV-visible absorption spectroscopy. The concentration of $\mathrm{MB}$ is proportional to the absorbance of $\mathrm{MB}$ according to the Beer-Lambert law, so the degradation efficiency of MB can be calculated by [40,41]:

$$
R=\frac{C_{0}-C}{C_{0}} \times 100 \%=\frac{A_{0}-A}{A_{0}} \times 100 \%
$$

where $A_{0}, A$, and $C_{0}, C$ are the absorbance and concentration of $\mathrm{MB}$ when the reaction time is 0 and $t$, respectively. The photocatalytic reaction rate depends on the concentration of the organic pollutants and can be described by the following kinetic model [15]:

$$
\text { rate }=-\frac{d C}{d t}=\frac{k K C}{1+K C}
$$

where $C$ is the concentration of $\mathrm{MB}(\mathrm{mg} / \mathrm{L})$ at any time, $t$ is the irradiation time, $k$ is the first-order rate constant of the reaction and $K$ is the adsorption constant of the pollutant on the photocatalyst. This equation can be simplified to a pseudo-first-order equation [34]: 


$$
\operatorname{Ln} \frac{C}{C_{0}}=-k K t=k_{\text {obs }} t
$$

in which $k_{o b s}$ is the observed first-order rate constant of the photodegradation reaction. The observed first-order rate constant for the photocatalytic degradation of $\mathrm{MB}$ on the nanocrystallines was calculated using plots of $\operatorname{Ln} C / C_{0}$ versus irradiation time.

\section{Conclusions}

This paper presented a simple method for preparation of efficient visible light photocatalytic materials, namely high purity $\mathrm{ZnS}$ and $\mathrm{CdS}$ nanoparticles, by a microwave irradiation route. The obtained $\mathrm{ZnS}$ and $\mathrm{CdS}$ nanoparticles had cubic and hexagonal structures respectively with average particle sizes of $4.3 \mathrm{~nm}$ and $10.1 \mathrm{~nm}$ corresponding to band gap energies of $4.22 \mathrm{eV}$ and $2.64 \mathrm{eV}$ respectively.

Photocatalytic degradation of methylene blue was carried out using physical mixtures of $\mathrm{ZnS}$ and $\mathrm{CdS}$ nanoparticles at different weight percentages under visible light irradiation. The results show that the photocatalytic activity of the samples depends on the weight percentage of $\mathrm{ZnS}$ in the physical mixture. The samples with a $\mathrm{ZnS}$ weight percentage of less than 50\% show a degradation efficiency equal to or more than pure CdS. The highest photodegradation of methylene blue was observed for a $\mathrm{ZnS}$ weight percentage of $20 \%$. In this case the degradation efficiency of the photocatalyst nanoparticles after 360 min illumination was about $73 \%$ with a reaction rate of $3.61 \times 10^{-3} \mathrm{~min}^{-1}$. The photodegradation efficiency was promoted by increasing the concentration of photocatalyst and the initial $\mathrm{pH}$ of the solution.

\section{Acknowledgments}

This work was supported by the Ministry of Higher Education of Malaysia under the FRGS and RUGS grants. The authors would also like to thank the staff of the Faculty of Science and Bioscience Institute of the University Putra Malaysia, who contributed to this work.

\section{References}

1. Jiang, R.; Zhu, H.; Li, X.; Xiao, L. Visible light photocatalytic decolourization of C. I. Acid Red 66 by chitosan capped CdS composite nanoparticles. Chem. Eng. J. 2009, 152, 537-542.

2. Sharma, M.; Jain, T.; Singh, S.; Pandey, O.P. Photocatalytic degradation of organic dyes under UV-visible light using capped ZnS nanoparticles. Sol. Energy 2012, 86, 626-633.

3. Torres-Martínez, C.L.; Kho, R.; Mian, O.I.; Mehra, R.K. Efficient photocatalytic degradation of environmental pollutants with mass-produced $\mathrm{ZnS}$ nanocrystals. J. Colloid Interface Sci. 2001, 240, 525-532.

4. Zhu, H.; Jiang, R.; Xiao, L.; Chang, Y.; Guan, Y.; Li, X.; Zeng, G. Photocatalytic decolorization and degradation of Congo Red on innovative crosslinked chitosan/nano-CdS composite catalyst under visible light irradiation. J. Hazard. Mater. 2009, 169, 933-940.

5. Wang, R.; Xu, D.; Liu, J.; Li, K.; Wang, H. Preparation and photocatalytic properties of $\mathrm{CdS} / \mathrm{La}_{2} \mathrm{Ti}_{2} \mathrm{O}_{7}$ nanocomposites under visible light. Chem. Eng. J. 2011, 168, 455-460. 
6. Andrade, G.R.S.; Nascimento, C.C.; Neves, E.C.; Barbosa, C.D.A.E.S.; Costa, L.P.; Barreto, L.S.; Gimenez, I.F. One-step preparation of CdS nanocrystals supported on thiolated silica-gel matrix and evaluation of photocatalytic performance. J. Hazard. Mater. 2012, 203-204, 151-157.

7. Pouretedal, H.R.; Norozi, A.; Keshavarz, M.H.; Semnani, A. Nanoparticles of zinc sulfide doped with manganese, nickel and copper as nanophotocatalyst in the degradation of organic dyes. J. Hazard. Mater. 2009, 162, 674-681.

8. Maji, S.K.; Dutta, A.K.; Srivastava, D.N.; Paul, P.; Mondal, A.; Adhikary, B. Effective photocatalytic degradation of organic pollutant by $\mathrm{ZnS}$ nanocrystals synthesized via thermal decomposition of single-source precursor. Polyhedron 2011, 30, 2493-2498.

9. Whang, T.-J.; Huang, H.-Y.; Hsieh, M.-T.; Chen, J.-J. Laser-induced silver nanoparticles on titanium oxide for photocatalytic degradation of methylene blue. Int. J. Mol. Sci. 2009, 10, 4707-4718.

10. Gou, Y.; Su, Z.; Xue, Z. A study on preparation and photocatalytic characterization of conjugated polymer/ZnS complex. Mater. Res. Bull. 2004, 39, 2203-2208.

11. Xie, Y.; Zhang, C.; Miao, S.; Liu, Z.; Ding, K.; Miao, Z.; An, G.; Yang, Z. One-pot synthesis of $\mathrm{ZnS}$ /polymer composites in supercritical $\mathrm{CO}_{2}$-ethanol solution and their applications in degradation of dyes. J. Colloid Interface Sci. 2008, 318, 110-115.

12. Li, J.-H.; Lu, A.-H.; Liu, F.; Fan, L.-Z. Synthesis of ZnS/dravite composite and its photocatalytic activity on degradation of methylene blue. Solid State Ionics 2008, 179, 1387-1390.

13. Wu, X.; Li, K.; Wang, H. Facile synthesis of $\mathrm{ZnS}$ nanostructured spheres and their photocatalytic properties. J. Alloy. Compd. 2009, 487, 537-544.

14. Li, Y.; He, X.; Cao, M. Micro-emulsion-assisted synthesis of $\mathrm{ZnS}$ nanospheres and their photocatalytic activity. Mater. Res. Bull. 2008, 43, 3100-3110.

15. Taghvaei, V.; Habibi-Yangjeh, A.; Behboudnia, M. Hydrothermal and template-free preparation and characterization of nanocrystalline $\mathrm{ZnS}$ in presence of a low-cost ionic liquid and photocatalytic activity. Physica E 2010, 42, 1973-1978.

16. Zhang, L.; Qin, D.; Yang, G.; Zhang, Q. The investigation on synthesis and optical properties of ZnS:Co nanocrystals by using hydrothermal method. Chalcogenide Lett. 2012, 9, 93-98.

17. Qiu, W.; Xu, M.; Yang, X.; Chen, F.; Nan, Y.; Chen, H. Novel hierarchical CdS crystals by an amino acid mediated hydrothermal process. J. Alloy. Compd. 2011, 509, 8413-8420.

18. Chai, L.; Du, J.; Xiong, S.; Li, H.; Zhu, Y.; Qian, Y. Synthesis of wurtzite ZnS nanowire bundles using a solvothermal technique. J. Phys. Chem. C. 2007, 111, 12658-12662.

19. Zhou, H.; Fan, T.; Zhang, D.; Guo, Q.; Ogawa, H. Novel bacteria-templated sonochemical route for the in situ one-step synthesis of ZnS hollow nanostructures. Chem. Mater. 2007, 19, 2144-2146.

20. Yadav, R.S.; Mishra, P.; Mishra, R.; Kumar, M.; Pandey, A.C. Growth mechanism and optical property of CdS nanoparticles synthesized using amino-acid histidine as chelating agent under sonochemical process. Ultrason. Sonochem. 2010, 17, 116-122.

21. Chang, S.-Q.; Kang, B.; Dai, Y.-D.; Zhang, H.-X.; Chen, D. One-step fabrication of biocompatible chitosan-coated $\mathrm{ZnS}$ and $\mathrm{ZnS}: \mathrm{Mn}^{2+}$ quantum dots via a gamma-radiation route. Nanoscale Res. Lett. 2011, 6, 591.

22. Chatterjee, A.; Priyam, A.; Das, S.K.; Saha, A. Size tunable synthesis of cysteine-capped CdS nanoparticles by $\gamma$-irradiation. J. Colloid Interface Sci. 2006, 294, 334-342. 
23. Sun, J.Q.; Shen, X.P.; Chen, K.M.; Liu, Q.; Liu, W. Low-temperature synthesis of hexagonal ZnS nanoparticles by a facile microwave-assisted single-source method. Solid State Commun. 2008, 147, 501-504.

24. Molaei, M.; Iranizad, E.S.; Marandi, M.; Taghavinia, N.; Amrollahi, R. Synthesis of CdS nanocrystals by a microwave activated method and investigation of the photoluminescence and electroluminescence properties. Appl. Surf. Sci. 2011, 257, 9796-9801.

25. Entezari, M.H.; Ghows, N.; Micro-emulsion under ultrasound facilitates the fast synthesis of quantum dots of CdS at low temperature. Ultrason. Sonochem. 2010, 18, 127-134.

26. Park, K.; Yu, H.; Chung, W.; Kim, B.-J.; Kim, S. Effect of heat-treatment on CdS and CdS/ZnS nanoparticles. J. Mater. Sci. 2009, 44, 4315-4320.

27. Poormohammadi-Ahandani, Z.; Habibi-Yangjeh, A. Fast, green and template-free method for preparation of $\mathrm{Zn1-xCdxS}$ nanoparticles using microwave irradiation and their photocatalytic activities. Physica E 2010, 43, 216-223.

28. Zhu, J.-J.; Wang, H. Synthesis of Metal Chalcogenide Nanoparticles. In Encyclopedia of Nanoscience and Nanotechnology; American Scientific Publishers: Stevenson Ranch, CA, USA, 2004; Volume 10, pp. 347-367.

29. Simmons, B.A.; Li, S.; John, V.T.; McPherson, G.L.; Bose, A.; Zhou, W.; He, J. Morphology of CdS nanocrystals synthesized in a mixed surfactant system. Nano Lett. 2002, 2, 263-268.

30. Seoudi, R.; Shabaka, A.; Eisa, W.H.; Anies, B.; Farage, N.M. Effect of the prepared temperature on the size of CdS and ZnS nanoparticle. Physica B 2010, 405, 919-924.

31. Zhao, J.; Yang, X. Photocatalytic oxidation for indoor air purification: A literature review. Build. Environ. 2003, 38, 645-654.

32. Das, D.P.; Biswal, N.; Martha, S.; Parida, K.M. Solar-light induced photodegradation of organic pollutants over CdS-pillared zirconium-titanium phosphate (ZTP). J. Mol. Catal. A 2011, 349, 36-41.

33. Chirita, M.; Grozescu, I.; Taubert, L.; Radulescu, H.; Princz, E.; Stefanovits-Bányai, É.; Caramalau, C.; Bulgariu, L.; Macoveanu, M.; Muntean, C. $\mathrm{Fe}_{2} \mathrm{O}_{3}$-Nanoparticles, physical properties and their photochemical And photoelectrochemical applications. Chem. Bull. 2009, 54, 1.

34. Xu, X.; Lu, R.; Zhao, X.; Xu, S.; Lei, X.; Zhang, F.; Evans, D.G. Fabrication and photocatalytic performance of a ZnxCd1-xS solid solution prepared by sulfuration of a single layered double hydroxide precursor. Appl. Catal. B 2011, 102, 147-156.

35. Antoniadou, M.; Daskalaki, V.M.; Balis, N.; Kondarides, D.I.; Kordulis, C.; Lianos, P. Photocatalysis and photoelectrocatalysis using $(\mathrm{CdS}-\mathrm{ZnS}) / \mathrm{TiO}_{2}$ combined photocatalysts. Appl. Catal. B 2011, 107, 188-196.

36. Roy, A.; De, G. Immobilisation of $\mathrm{CdS}, \mathrm{ZnS}$ and mixed $\mathrm{ZnS}-\mathrm{CdS}$ on filter paper: Effect of hydrogen production from alkaline $\mathrm{Na}_{2} \mathrm{~S} / \mathrm{Na}_{2} \mathrm{~S}_{2} \mathrm{O}_{3}$ solution. J. Photoch. Photobio. A 2003, 157, 87-92.

37. Franco, A.; Neves, M.C.; Carrott, M.M.L.R.; Mendonça, M.H.; Pereira, M.I.; Monteiro, O.C. Photocatalytic decolorization of methylene blue in the presence of $\mathrm{TiO}_{2} / \mathrm{ZnS}$ nanocomposites. J. Hazard. Mater. 2009, 161, 545-550.

38. Tang, W.Z.; Huang, C.P. Inhibitory effect of thioacetamide on CdS dissolution during photocatalytic oxidation of 2,4-dichlorophenol. Chemosphere 1995, 30, 1385-1399. 
39. Davis, A.P.; Huang, C.P. The photocatalytic oxidation of sulfur-containing organic compounds using cadmium sulfide and the effect on CdS photocorrosion. Water Res. 1991, 25, 1273-1278.

40. Wang, K.;Yu, L.;Yin, S.;Li, H.; Li, H. Photocatalytic degradation of methylene blue on magnetically separable $\mathrm{FePc} / \mathrm{Fe}_{3} \mathrm{O}_{4}$ nanocomposite under visible irradiation. Pure Appl. Chem. 2009, 81, 2327-2335.

41. Abdollahi, Y.; Abdullah, A.H.; Zainal, Z.; Yusof, N.A. Photocatalytic degradation of p-Cresol by zinc oxide under UV irradiation. Int. J. Mol. Sci. 2011, 13, 302-315.

(C) 2012 by the authors; licensee MDPI, Basel, Switzerland. This article is an open access article distributed under the terms and conditions of the Creative Commons Attribution license (http://creativecommons.org/licenses/by/3.0/). 